\title{
Gary Hawke
}

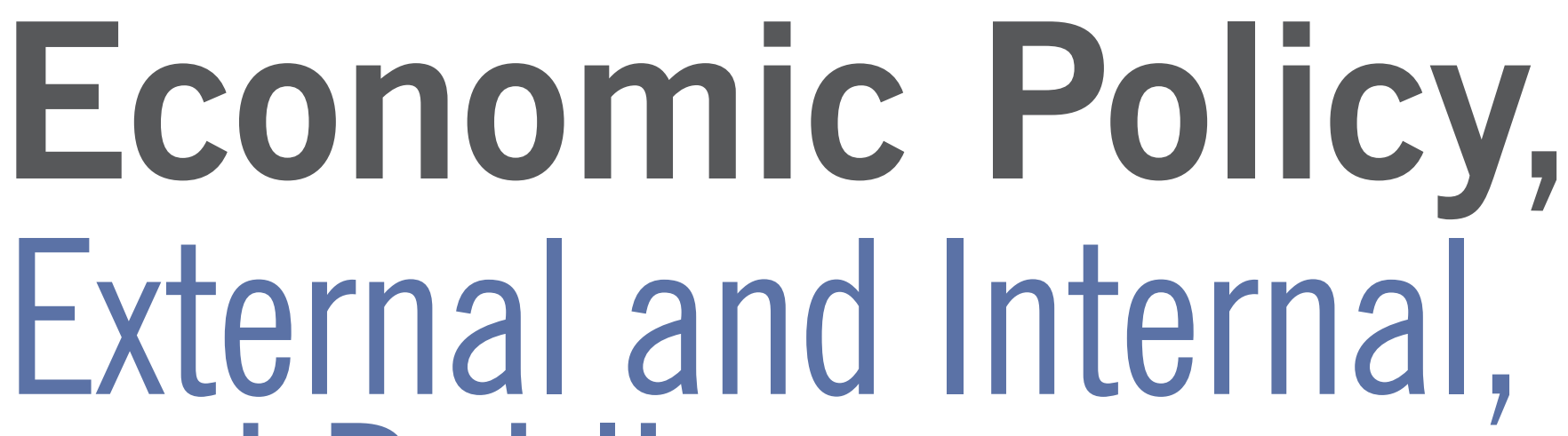

and Public

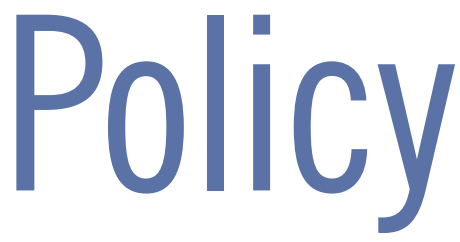

Ross Garnaut delivered a Holmes Lecture superbly crafted

to honour Frank Holmes. With his background in all of academic economics, policy development, diplomacy and

business governance, as well as a longstanding personal acquaintance with Frank, Ross is as well qualified as anybody for a Holmes Lecture, and he more than delivered on his qualifications.

Ross's economic theory is deployed discreetly. Not only does his lecture have diagrams but no equations, but

also most of the theorising is implicit. It is, however, sophisticated and carefully developed. Perhaps the influence of

Emeritus Professor Gary Hawke was foundation head of the School of Government, 2003-08. $\mathrm{He}$ is a longstanding member and former chair of the board of the New Zealand Pacific Economic Cooperation Council, Senior Fellow at the New Zealand Institute of Economic Research and member of the Academic Advisory Council of the Economic Research Institute for ASEAN and East Asia (Jakarta). economic theory is most apparent in the concept of 'maturation' of economic growth, the eventually spreading of economic growth across all societies, with an implicit end-point when all have a common real per capita income and rate of growth. This is the standard economic concept of equilibrium, quickly related to both the various long-run tendencies of classical economics and the more recent creations of dynamic equilibria. It is an analytical device; it is not simple-minded description. It promotes exploration of possible disruption of a smooth transition to equilibrium, and what are offered as counter-examples to equilibrium analysis are often misconceived. Ross has used a similar device in earlier work: one of the most interesting ideas in his work on climate change, albeit often ignored, was the identification of equal per capita emissions as an equilibrium. Discussion about blame for historic emissions and fair entitlements to emission-generating development could fruitfully have been avoided by wider understanding of the 
role of equal per capita emissions.

Ross does not always use the equilibrium notion. One area from which it is absent, more prominent in his earlier work, and in his most recent book, on the Australian economy (Garnaut, 2013), than in the Holmes Lecture, is the choice of interest rate for evaluating investment projects. High interest rates imply that costs and benefits in the distant future have little impact on current decisions; their present value is discounted to close to zero. That is uncongenial to those who advocate attaching weight to the welfare of distant generations (or who is an argument that an equilibrating process will equate the two, but it is interesting mainly for directing attention to departures from the conditions under which the argument is valid. Accounting for capital losses is not simple, and nor are the distributional consequences of funds supporting pension entitlements. Following Keynes, Ross sees a likelihood that savings will tend to outrun the desire to invest, although he relies on ageing rather then satiation. Keynes expected material desire to be satisfied so that working hours would be diminished, but subsequent experience has been

\section{... journalistic commentary is dominated by suggestions that the present generation is unusual in not being able to look forward to future generations being better off than current experience.}

opportunistically use the interests of distant descendants to justify imposition of their own preferences). But choice of the appropriate interest rate is not arbitrary or even simply a value to be determined by a political process. It involves assessment of community preferences with the aid of equilibrium devices such as Ross deploys effectively elsewhere. There is no simple solution determining community preferences is inevitably complicated and contentious - but imposition of a personal preference is no solution.

Interest rates are a major link between economic theory and policy analysis. Ross pursues several aspects, all persuasively. He very effectively limits any echoes of Piketty's argument in the title of his Holmes Lecture, 'Global development in the 21 st century', since he expects interest rates to be low, preferring the analysis of Keynes' 'Economic possibilities for our grandchildren' (Keynes, 1931, pp.35874). The sufficiency of an excess of interest rates over the rate of growth to generate inequality is dubious - there dominated by rising aspirations at least keeping pace with increased production. Should we perhaps expect that the balance of investment plans and desired savings will also change? Perhaps by an equilibrating process?

It certainly seems unlikely that there will be any reversal in the demographic trends which create an expectation for savings intentions to exceed investment plans. The dominant demographic force is fertility and incentives are heavily weighted towards continued reduction in fertility. The material welfare of households is not promoted by children; social norms increasingly restrict child labour everywhere; and parents more and more recognise that the life chances of their children depend on expensive inputs, both time and diversion of household resources. There is little reason to doubt Ross's expectation of continued spread of a general experience of ageing. The 'modern economic growth' about which he writes is not the 'modern economic growth' which Kuznets discerned as the historical norm when he was writing nearly 50 years ago.
Kuznets then found a generally positive association between population growth and growth of real per capita incomes (Kuznets, 1966). Fertility caught up with declining mortality, and came to dominate the spreading of higher income levels both within developed countries and as growth spread internationally.

It is not impossible that we will be surprised. Expectations of declining populations were widespread in the 1930s, as analysts established that population growth rates had been declining from the 19th century, the trend being led in rich countries. Then, as now, analysts explained the trend through the rising relative cost of children, their lesser value as sources of labour and their greater requirements of investment. But from the 1940s to the 1960 s the trend was reversed, and a surge in fertility produced the baby boom generation which features in current discussion. Analysis of the baby boom is complex, but the central intuition is that after the experience of the Great Depression in the 1930s, parents in newly-formed households confidently expected that they would be able to provide children with better starts in life than they had themselves experienced, sufficiently so as to permit them to have larger families.

Currently, journalistic commentary is dominated by suggestions that the present generation is unusual in not being able to look forward to future generations being better off than current experience. It is not very secure, but surveys in several countries suggest that it is widespread. If it is reversed, could we see some repetition of the baby boom? Perhaps, but it looks like a very long shot indeed.

Other mechanisms to reverse declining fertility have been suggested. Many women who delay childbearing until late in their 30s encounter difficulty in conceiving and pregnancy, and medical advice is increasingly insistent that the best years for childbearing are much younger. The direct impact of such advice is likely to be small, given widespread scepticism of medical authority outside a strictly clinical context, but an underlying concern with social institutions which constrain childrearing at earlier ages may well be strengthened. It has long been 
common to contrast Italy and Sweden: in countries where, as in Italy, women are mostly forced to choose either family or employment fertility will be lower than in countries, such as Sweden, where employment conditions and accessibility of child care are more conducive to combining childrearing with advancement in a career. The impact of responses such as different gender allocations of responsibilities for childrearing, or flexible hours of work, have been limited, and a substantial impact would have to come from changes in occupations such as the law and finance away from using long hours of concentrated work to screen for rapid professional advancement. Quick change cannot be expected.

Hence the demographic trends expected by Ross Garnaut are strongly based. But perhaps the link between ageing and economic growth will change? Ross is well aware of possibilities such as more creative use of mature and aged workers, but, while prejudice should always be challenged, there can be little doubt that age generally reduces both initiative and enthusiasm for change and it is effective management of change rather than 'structural reform' that should be the focus. Any weakness in the link between ageing and economic growth is likely to be directly in the savingsinvestment nexus.

The proposition that ageing generates increased desired saving is not unqualified. It is more true of individuals of working ages than it is of the aged, who dissave, and is therefore less than self-evident in the aggregate. Total savings may be unchanged as those in employment save more but the aged dissave more quickly and for longer. (In reality, private savings may be outweighed by public saving trends.) At an international level, the extraordinary saving of Chinese in recent times and the current trends in Chinese economic strategy mean that the savings propensity there is likely to decline, and China is sufficiently large to affect world totals.

Pessimistic expectations about the propensity to invest are usually derived from productivity trends, and eventually from assessments of technology change. The reading is contested. Debate has been most intense in the US, and even there it may be read as favouring those who see less a decline in the impact than changes in its incidence. Economic historians are accustomed to tracing the productivity gains of the iron and steel industry in the classical industrial revolution, observing the introduction of major technology innovations such as the blast furnace, and then recognising that most productivity gains came from incremental improvements between major innovations rather than directly from their introduction. We should expect the same to be true of current innovations such as the internet, and the
The successful mechanisms are all much less visible than periodic accounts of failed international conferences, which have many of the characteristics of circuses. In Dog Days, Ross observes that informal understandings 'were probably more ambitious than they would have been in a notionally legally binding agreement negotiated by all countries. Formal negotiations make country representatives defensive' (Garnaut, 2013, p.185). His pragmatism is appealing. So would be its extension to considering the future balance of investment and savings intentions.

\section{Anybody who follows Asian discussions will be aware that 'inclusive growth' looms much larger there than it does in standard 'Western' discussions.}

sensors and robots that are starting to have significant impacts. We should also be careful to avoid assessing technology trends from trends in machines. Even though technology changes fastest when it involves management of machinery through repetitive tasks which can readily be taught, the greatest impact of technology has historically tended to come from organisational changes, often at a more aggregate level than individual firms. These are usually less readily observable and more likely to be recognised only in retrospect.

Ross gives an optimistic view of future development in any case. $\mathrm{He}$ notes especially the impact of technology change on carbon emissions, through improvements in the carbon intensity of production, cost-reducing innovations in low-carbon technologies, the incentives of desirable health effects, and realistic mobilisation of international cooperation. (Ross treats reductions in the cost of low-emission technologies as part of mitigation and criticises reliance on adaptation at the expense of mitigation, but the categorisation is not important. Technical progress is.)
Ross is interested in inclusive development across the whole of humanity'. Anybody who follows Asian discussions will be aware that inclusive growth' looms much larger there than it does in standard 'Western' discussions. It is not just a concession to political activists, or a contrivance which is useful for evading prescriptions for change. Rather, it reflects an ultimate aim of community-building, the construction of a harmonious as well as prosperous society. Perhaps the single most important point in the Holmes Lecture is the quotation and discussion around chart 7 taken from the World Bank policy research working paper by Lakner and Milanovic. Distributional issues are global, not parochial. Broad trends in technology have generated incomes for many (but not all) of the world's relatively poor, and the relatively disadvantaged in the three decades shown in this chart were 'people around the 80th and 90th percentiles - well off on a world scale, corresponding to workers in the developed countries'. Most of the attributions of responsibility to specific government interventions in individual countries look almost trivial. ${ }^{1}$ Indeed, 
Ross saw some parallel with Heinz Arndt's query whether societies for the relief of genteel ladies were ever socially desirable. However, distributional issues have to be taken seriously, for moral reasons and to ensure that societies remain conducive to progress. Ross remains optimistic, as is implicit in his 'maturation' concept. He specifically ruled out any suggestion that Africa or anywhere else has to remain poor.

To find a single government with major influence we look to China. Ross draws on all his diplomatic experience, and the phenomenal rates, while Chinese demand for dairy products is likely to continue to grow. An emphasis on services, such as education, is less biased in favour of New Zealand, and 'dairy products' involves much more than 'farm products', with other inputs able to be sourced from elsewhere than New Zealand. These are important direct influences from China, but their distributional consequences may well be dwarfed by the subjection of all low-skilled employment in New Zealand and Australia to competition from India and eventually Africa, and

\section{It is easy to endorse Ross's call for strengthening of the 'independent centre' in the policy community, as Frank Holmes would certainly do, but we may doubt whether the greatest challenge comes from using political and policy institutions for private interests.}

knowledge his access has made available to him, to create a very positive picture of China's development. In his book Dog Days he has more room for qualifications than he did in the Holmes Lecture, or even in the seminar in Wellington where he discussed China's new development model. The book therefore includes: 'The big currents of economic development are inherently uncertain. China may fail in the implementation of its ambitious structural reform' (Gartnaut, 2013, p.270). But he is surely right that success is more likely than any of the scenarios painted by those who cannot refrain from expecting Armageddon in some form.

The implications for Australia and New Zealand are profound. We benefited from Chinese demand, for minerals in the case of Australia, dairy produce in the case of New Zealand. New Zealand is now better placed than Australia, since China's 'new development model' will reduce emphasis on construction and on the 'metals' sector, which grew at increasing competition from the booming Chinese education sector for what is now relatively sheltered educated labour in New Zealand and Australia.

In pursuing the implications of such analyses, Ross puts a lot of weight on exchange rates. He is not afraid to use standard 'Keynesian' analysis. For example, he describes the Chinese policy response to the global financial crisis as 'Keynesian'. The term was originally used in circumstances such as the Second World War, when community cohesion had a strong extraneous source, and continued in the 1950s and 1960s when the state was widely accepted as the embodiment of collective will. It became contested as the stagflation of the 1970s generated more intense rivalry within societies, and government interventions were as much likely to be anticipated and countered as accepted as expressions of collective interest. The implication if Ross's analysis of China's experience is correct is that its government is more likely to be accepted as acting in the collective interest than is now usual for governments of 'Western' economies.

Trust in governments may be engendered in various ways, through voluntary acquiescence earned by experience or through fear, or perhaps Ross was simply relying on older analysis. The latter possibility seems to be the case with his insistence on the real exchange rate in his criticism of Australian economic policy in response to the resources boom and the subsequent 'dog days'. International competitiveness is always important, but in the contemporary international economy it cannot be related only to the prices of traded goods and services. Exchange rate changes must also be related to international investment, both valuation of stocks of cross-border capital flows and impacts on revenue flows across borders from outward and inward international investment. Ross is surely right that in Australia, as in New Zealand, concern about Chinese investment is mostly xenophobic, just as were earlier worries about Japanese investment, or even earlier antagonism to American investment. But those international investment flows mean that it is no longer adequate to think only about domestic incomes, the real exchange rate, and competitiveness of exports.

Ross's principal concern is less with economic policy than with public policy in general. His target is 'more overt and less constrained interventions by vested interests in the developed countries' policy-making process, their evident success in influencing policy in the 21st century, and the associated decline in aggregate economic performance and the skewed distribution of incomes and wealth'. It is a theme much discussed in the US, and Dog Days develops the analysis for Australia with several persuasive accounts of specific interests unduly influencing the policy process. The Australian examples of mining interests gaining strategic political positions or manipulating the policy process are even more blatant than any well-documented concerns in the US, where the greatest worry is the implicit collaboration established through major contributions to campaign funding. (New Zealand experience is trivial by comparison, but it is easy to think of phrases like 'eternal vigilance'. Ross is 
concerned about corporate funding of politics in both Australia and the US, and he includes trade union funding in that.)

It is easy to endorse Ross's call for strengthening of the 'independent centre' in the policy community, as Frank Holmes would certainly do, but we may doubt whether the greatest challenge comes from using political and policy institutions for private interests. There is now more assertiveness of specific interests of all kinds, including activists who dress themselves as guardians of the public interest, and who exploit any opportunity to advance their enthusiasm at the expense of deliberative policy analysis which considers unintended consequences and focuses on feasible alternatives rather than some alleged utopia which can be reached in one easy step. Ross drew to our attention the caution in Condliffe's 1951 The Commerce of Nations: 'It is always dangerous to entrust the final decisions of social policy to those who stand to gain from an immediate course of action.'

In this regard as in others, Ross skilfully links his interest in Australia to understanding of the wider world. Tension between political and economic development is a standard component of analysis of contemporary China, but it is not often related to worrying trends in governance in developed democracies. Yet both are concerned with governing in the interests of the public. Democracy is more than the existence of elections and alternation of power among parties. China's sensitivity to its public, obviously limited in some respects, is shown by responsiveness to the health effects of pollution, and its thinkers will now be less concerned with American election strategies than with watching whether the Singaporean approach to securing order and harmony as well as material prosperity will survive loss of the direct influence of Lee Kuan Yew.
In all of the employment of economic theory, sophisticated even when not entirely convincing, the discussion of economic strategy, and the deeper issues of public policy, Frank Holmes would have found much to approve in this lecture, and more to engage with further. We benefit from the interaction of Ross and Frank.

\footnotetext{
1 Hwok-Aun Lee in 'Some Malaysian inequality measures more equal than others' (East Asia Forum, 26 February 2015) suggests that 'Malaysians are simply conflating the general economic environment with inequality', and this has applicability much wider than Malaysia.
}

\section{References}

Garnaut, R. (2013) Dog Days: Australia after the Boom, Collingwood, Vic: Redback

Keynes, J.M. (1931) Essays in Persuasion, London: Macmillan (originally published in the Nation and Athenæum, 11 and 18 October 1930)

Kuznets, S. (1966) Modern Economic Growth: rate, structure and spread, New Haven; London: Yale University Press

\section{IGPS Public Forums in July - RSVP Essential}

\section{A More Inclusive New Zealand Forum}

\section{July 9:Ooam - 5:30pm Te Papa}

\section{About the Forum}

The purpose of the forum is to bring government, non-government and community organisations together to discuss ideas and action on how to create a more inclusive New Zealand. The goal is to develop a shared understanding of the key issues that will allow every New Zealander to fully participate in the economy and society.

The forum will be designed to encourage conversations and discussion and connecting relationships.

\section{Identifying What Works} Using Randomised Control Trials in Public Policy

7 July 9:ooam - 4:0opm Pipitea Campus

\section{About the Symposium}

The aim of this free, full-day symposium is to build more knowledge and capability around RCTs, both in government and

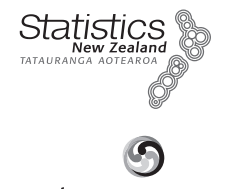
greater WELLINGTON REGIONAL COUNCIL among interested parties. There will be presentations by international experts, a panel on examples, keynotes on 'Importance of Evidence' and 'Broader Issues of RCT's' and much more.
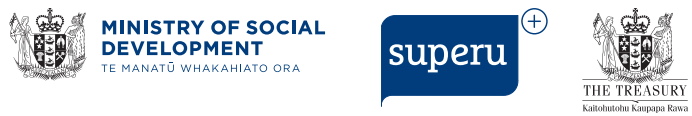

VICTORIA

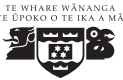

Institute for Governance and Policy Studies

A research institute of the School of Government 